\title{
Developmental Differences in the Effects of Repeated Interviews and Interviewer Bias on Young Children's Event Memory and False Reports
}

\author{
Jodi A. Quas, \\ Department of Psychology and Social Behavior, University of California, Irvine. \\ Lindsay C. Malloy, \\ Department of Psychology and Social Behavior, University of California, Irvine. \\ Annika Melinder, \\ Department of Psychology, University of Oslo, Oslo, Norway, and Norwegian National Academy \\ of Science and Letters, Oslo, Norway.
}

\author{
Gail S. Goodman, \\ of Oslo; and Norwegian National Academy of Science and Letters. \\ Michelle D'Mello, and \\ Department of Psychology, University of California, Davis. \\ Jennifer Schaaf \\ Child Development Institute, University of North Carolina at Chapel Hill.
}

Department of Psychology, University of California, Davis; Department of Psychology, University

\begin{abstract}
The present study investigated developmental differences in the effects of repeated interviews and interviewer bias on children's memory and suggestibility. Three- and 5-year-olds were singly or repeatedly interviewed about a play event by a highly biased or control interviewer. Children interviewed once by the biased interviewer after a long delay made the most errors. Children interviewed repeatedly, regardless of interviewer bias, were more accurate and less likely to falsely claim that they played with a man. In free recall, among children questioned once after a long delay by the biased interviewer, 5 -year-olds were more likely than were 3-year-olds to claim falsely that they played with a man. However, in response to direct questions, 3-year-olds were more easily manipulated into implying that they played with him. Findings suggest that interviewer bias is particularly problematic when children's memory has weakened. In contrast, repeated interviews that occur a short time after a to-be-remembered event do not necessarily increase children's errors, even when interviews include misleading questions and interviewer bias. Implications for developmental differences in memory and suggestibility are discussed.
\end{abstract}

\section{Keywords}

children; memory; suggestibility; repeated interviews; false report 
Although it is well accepted that memories are not exact replicas of prior experiences but instead are reconstructions (Loftus, 1979), the nature of these reconstructions and the effects of developmental and contextual influences on them remain debated. One noteworthy debate has focused on the effects of repeated interviews on children's memory and suggestibility. In particular, concerns have been raised that the more often a child is interviewed, the more often misinformation might be presented—intentionally or inadvertently-leading to increased inaccuracy over time. Moreover, repeated demands for a child to retrieve information from memory may increase confabulations due to social pressure. Despite these concerns, studies of children's memory for experienced events generally suggest that repeated interviews can improve performance by facilitating recall and reducing forgetting (e.g., Howe, Courage, \& Bryant-Brown, 1993; Peterson, 1999). Yet, in a second line of research, specifically when children are suggestively questioned about false events, adverse effects of repeated interviews appear to emerge (e.g., Bruck, Ceci, \& Hembrooke, 2002; Leichtman \& Ceci, 1995).

A simple explanation for the different patterns of results is that repeated interviews benefit memory when the to-be-remembered event is true and distort memory when the to-beremembered event is false. However, a number of other factors likely contribute to the evident reduction in accuracy when children are repeatedly interviewed about fictitious events, making the simple explanation premature. For instance, studies concerning children's false event reports following repeated interviews often began with an interviewer explicitly stating that the false events occurred (e.g., Ceci, Huffman, Smith, \& Loftus, 1994). The interviewers' biased statement, in addition to or instead of the interview repetition, may well have affected children's accuracy. In addition, children's false reports following repeated interviews were often compared with their reports in earlier interviews (e.g., Bruck et al., 2002). Yet, in order to draw conclusions about the effects of repeated interviews per $\mathrm{se}$, one needs to compare performance of children exposed to repeated interviews with the performance of children exposed to a single interview matched in delay to that of children exposed to repeated interviews.

The purpose of the present study was to disentangle the effects of repeated interviews and interviewer bias and, in doing so, to determine more precisely how repeated interviews affect children's memory and false reports. Also of interest was whether the effects of repeated interviews vary across development. Two age groups were thus included: 3- and 5year-olds, targeted for theoretical and practical reasons. Theoretically, compared with older preschoolers, younger preschoolers forget more quickly (Baker-Ward, Gordon, Ornstein, Larus, \& Clubb, 1993), have more limited ability to monitor the sources of their memories (Bright-Paul, Jarrold, \& Wright, 2005; Lindsay, Johnson, \& Kwon, 1991; Poole \& Lindsay, 1995; see also Roberts, 2002), are more trusting of adults' statements - even when adults have a history of providing inaccurate information (Clement, Koenig, \& Harris, 2004; Leichtman \& Ceci, 1995; Welch-Ross, 1999), and are more susceptible generally to suggestive interview tactics (Ceci, Huffman, et al., 1994; Goodman, Bottoms, SchwartzKenney, \& Rudy, 1991; Poole \& Lindsay, 2001). Practically, concerns in legal contexts about the malleability of memory are often greatest when preschoolers, as opposed to older children or adults, allege to have experienced or witnessed a crime (Ceci \& Bruck, 1998; Quas, Thompson, \& Clarke-Stewart, 2005), and repeated interviews are commonplace in forensic contexts (Goodman et al., 1992; Malloy, Lyon, \& Quas, 2007). Knowledge concerning younger and older preschoolers' performance following exposure to repeated interviews and biased interviewers can provide insight into developmental changes in the influence of contextual characteristics on children's eyewitness capabilities. 


\section{Repeated Interviews and Children's Memory and Suggestibility}

There are several reasons why repeated interviews may benefit memory. As indicated earlier, repetition may reduce forgetting because original event details are rehearsed during intervening interviews (Fivush \& Schwarzmueller, 1995; Gordon, Baker-Ward, \& Ornstein, 2001; Howe et al., 1993; Ornstein, 1995; Ornstein, Baker-Ward, Gordon, \& Merritt, 1997), a phenomenon sometimes termed an inoculation effect (Brainerd \& Ornstein, 1991; Gordon et al., 2001; Howe, 1991). Similarly, when questions repeatedly probe for particular event details, children learn what is important to recount and can focus on this information (e.g., Fivush \& Schwarzmueller, 1995). Finally, because intervening interviews serve as reminder cues and may activate additional information stored in memory, repeated interviews could lead to reminiscence (remembering new information across interviews) or hypermnesia (an increase in the total amount of details remembered across interviews; Erdelyi \& Becker, 1974).

Although studies have not found evidence for hypermnesia in children following repeated interviews, especially when interviews occur following a delay (e.g., LaRooy, Pipe, \& Murray, 2005), studies have revealed benefits of repetition in terms of greater reminiscence, decreased forgetting, and often increased resistance to misleading suggestions (e.g., BakerWard, Hess, \& Flannagan, 1990; Goodman, Hirschman, Hepps, \& Rudy, 1991; Howe et al., 1993; LaRooy et al., 2005; Ornstein, Gordon, \& Larus, 1992). For instance, following repeated interviews, young children can provide detailed and accurate accounts of a range of events, even highly stressful experiences (e.g., Fivush, Sales, Goldberg, Bahrick, \& Parker, 2004; Peterson, Moores, \& White, 2001). Also, in studies in which misinformation was presented, for example, with the interviewer asking yes-no questions about false details, children's memory accuracy often remained high across interviews, with few intrusions occurring in later questioning sessions (e.g., Ornstein et al., 1992). In fact, Goodman, Bottoms, et al. (1991) found that children's accuracy to misleading (i.e., false suppositional) questions increased across repeated interviews as children gained experience answering these questions. Thus, when children are repeatedly queried about true events, even when misleading questions are asked, interview repetition does not necessarily inhibit performance. Instead, repeated interviews may facilitate children's ability to maintain accurate reports over time.

As mentioned, repeated interviews appear to adversely affect performance when children are questioned about never-experienced (i.e., false) events. Theoretically, the repeated interviews increase the familiarity of false events. Because familiarity is often taken as evidence that an event occurred, children may confuse the source of their knowledge about false events as being due to actual experience (Ceci, Huffman, et al., 1994), a pattern consistent with source-monitoring perspectives concerning memory and suggestibility (Lindsay et al., 1991; Poole \& Lindsay, 1995; Roberts \& Blades, 2000). Also, according to fuzzy trace theory (Brainerd \& Reyna, 1990; Reyna \& Brainerd, 1995), compared with gist memory (i.e., memory for overall event meaning), verbatim memory (i.e., memory for surface features of the event) contains more details, fades more quickly, and is relied on relatively more by younger than older children. If children are exposed to misinformation during repeated interviews, young children in particular may incorporate the false verbatim information into their immediate memory accounts, thereby increasing inaccuracies (e.g., Brainerd \& Reyna, 1990, 1996). Finally, when interviews are repeated, children may assume that their earlier responses were incorrect, leading to inaccuracies over time due to social pressure (e.g., Siegal, Waters, \& Dinwiddy, 1988).

Several studies confirm these possibilities and reveal remarkably high error rates among children exposed to repeated interviews about fictitious events (e.g., Bruck et al., 2002; 
Ceci, Loftus, Leichtman, \& Bruck, 1994). Leichtman and Ceci (1995), for instance, questioned preschool-age children on multiple occasions about a man's visit to their class. For a subset of the children, the interviewer began by providing highly biased statements indicating that the man was clumsy, routinely damaged property, and had done so during his former visit (in fact the visit had been uneventful). In a final interview, a large percentage of these children falsely reported that the man engaged in the alleged activities. In another study, Bruck et al. (2002) interviewed children about two true (e.g., helping a class visitor who hurt her ankle) and two false (e.g., helping a lady find her monkey) events; within each type, one was positive and one was negative. After five highly suggestive interviews, 75\% of children assented to the false negative event, and assent rates increased with repeated interviewing for the true-negative, false-negative, and false-positive events.

Although the aforementioned studies highlight the potential for dramatic errors in children's accounts, errors often attributed to the children having been repeatedly interviewed, several other methodologically important factors may also have contributed to the evident results, highlighting the need for clarification concerning when and how repeated interviews affect children's false reports. First, as mentioned, several false event studies began with the interviewer explicitly telling children that the events occurred, for instance, by saying that their parents indicated the events took place, by telling children to imagine the events occurring, and/or by telling children that their friends already confirmed the events' occurrence (Bruck et al., 2002; Ceci, Huffman, et al., 1994). Such highly biased statements and interviewer pressure can lead to false reports even in a single interview (e.g., Garven, Wood, Malpass, \& Shaw, 1998; Quas et al., 1999; Thompson, Clarke-Stewart, \& Lepore, 1997). It is thus critical to determine whether simply repeatedly interviewing children about a false event is sufficient to produce considerable errors or whether a biased interviewer, alone or in conjunction with repeated interviews, underlies children's inaccuracies.

Second, in previous studies, children's false reports during a final interview were often compared with their own reports from earlier time points (e.g., Bruck et al., 2002; Ceci, Loftus, et al., 1994). Few studies have included a single interview condition in which the delay between the to-be-remembered event and the memory interview matched the delay between the to-be-remembered event and the final interview for children repeatedly questioned. One exception is a clever study conducted by Melnyk and Bruck (2004) concerning the effects of timing and repetition of misinformation on children's later memory and suggestibility. Five-year-olds experienced a magic show. Some were then exposed to misinformation sessions after varying delays, and a control group was not exposed to misinformation sessions. Later, children's memory was tested. Findings indicated that repeated interviewing heightened misinformation effects when children were exposed to misinformation both shortly after the event and shortly before the memory test. Although the study did not investigate children's reports of a false event, did not include children of different ages, and did not test the effects of highly biased interviewer statements and behaviors, findings indicated that repeated exposure to misinformation may increase children's errors.

A third important factor that has implications for the effects of repeated interviews concerns children's age. Compared with older children, younger children have weaker memory traces (Brainerd \& Reyna, 1998; Schneider, 2002) and are more susceptible to misleading suggestions (e.g., Poole \& Lindsay, 2001). With age, children can increasingly rely on their memory representations to refute an interviewer's highly biased statements. Moreover, when a long time has passed between a to-be-remembered event and an interview, age differences in the effects of interviewer bias may become exaggerated because of young children's tendency to incorporate verbatim information provided by an interviewer (e.g., via highly 
biased statements) into their immediate memory accounts, a possibility in need of direct experimental investigation.

\section{Summary}

In summary, controversies concerning the effects of repeated interviews on children's memory and false reports have been difficult to resolve because of methodological differences across studies. To determine, more precisely, how repeated interviews affect children's performance, one needs to separate experimentally repeated interviews and interviewer bias. It is equally important to include children interviewed only once, whose delay between a to-be-remembered event and a memory interview matches that of children repeatedly interviewed. Finally, because effects may vary developmentally, it is critical to include children across ages during which rapid cognitive and social changes are occurring. The present study was designed to address these issues and to provide new insight into developmental differences in the effects of repeated interviews and interviewer bias on children's memory and false reports.

\section{Present Study}

\section{Overview}

In this study, 3- and 5-year-olds came to a research laboratory and played alone. They then returned for either one (single interview condition) or three (repeated interview condition) interviews about what happened when they played. For children interviewed once, the delay between the play event and interview was 3 weeks. For children interviewed repeatedly, each interview took place after a 1-week delay; thus, the final interview took place 3 weeks after the play event. These delays were selected to be comparable to those used in other repeated interview studies (e.g., Goodman, Bottoms, et al., 1991; Leichtman \& Ceci, 1995; Ornstein et al., 1992). At the outset of each interview, half of the children were questioned by an interviewer who created a highly biased context that implied children had played with a man (biased interviewer condition). The other half of the children were questioned by an interviewer who was not biased (control interviewer condition). The interview(s) contained free-recall and direct questions, several of which were misleading in that they concerned playing with the man who was not present.

\section{Hypotheses}

Two main effects were anticipated. Consistent with a large body of research (e.g., BakerWard et al., 1993; Leichtman \& Ceci, 1995; Peterson, 1999; Quas \& Schaaf, 2002), memory was expected to improve, and false reports were expected to decrease with age. Also, children questioned by the biased interviewer were expected to be more likely to claim that they played with the man than were children questioned by the control interviewer (e.g., Garven et al., 1998; Thompson et al., 1997). These main effects were expected to be subsumed by several interactions. Among children repeatedly interviewed, children, especially 3-year-olds, questioned by the biased interviewer were expected to make the greatest number of false reports (e.g., Bruck et al., 2002; Ceci, Loftus, et al., 1994).

Repeated exposure to the biased interviewer should increase the familiarity of the false event and the potential for source-monitoring failure (Lindsay et al., 1991), with this increase being particularly noteworthy in 3-year-olds because of their generally weaker memory traces (e.g., Brainerd \& Reyna, 1996). Five-year-olds interviewed repeatedly by the control interviewer were expected to make the fewest number of false reports, similar to studies revealing beneficial effects of repetition (e.g., Goodman, Bottoms, et al., 1991; Ornstein et al., 1992). Children interviewed once by the control interviewer were expected to perform more poorly than were children interviewed repeatedly by the control interviewer because of the former children's longer delay between the play session and the first interview (e.g., 
Howe et al., 1993; Peterson, Pardy, Tizzard-Drover, \& Warren, 2005). Finally, in general, the effects of interview bias were expected to be more robust in 3- than in 5-year-olds (e.g., Ceci, Huffman, et al., 1994; Ceci, Loftus, et al., 1994).

\section{Method}

\section{Participants}

Seventy-five children, 38 3-year-olds $(M=40.95$ months, range $=37-47$ months $)$ and 375 year-olds ( $M=65.97$ months, range $=60-71$ months $)$, composed the final sample. Most participants $(78.1 \%$ ) were Caucasian; $2.7 \%$ were Hispanic, $1.4 \%$ were African American, $5.5 \%$ were Asian, and $12 \%$ were multiethnic. Families were primarily middle or upper middle class, and $83 \%$ and $81 \%$ of the mothers and fathers, respectively, had a bachelor's degree or higher. Within each age, children were randomly assigned to interview repetition and interviewer bias conditions (boys and girls were equally represented). Five additional children were tested but were excluded from the final sample: Two children's mean memory performance was over three standard deviations larger than any other child in their condition; one interviewer did not adhere to the protocol, and the 3 children she interviewed were subsequently dropped.

\section{Materials and Procedures}

Overview-The study design is presented in Figure 1. The play event was identical for all children and consisted of playing alone in a room. Children in the repeated interview condition returned for three subsequent weekly memory interviews. Children in the single interview condition returned for one interview 3 weeks after the play event. At the outset of each interview, biased interviewers provided false statements suggesting that children had interacted with a man in the playroom. Control interviewers provided no such statements. All children were asked direct (i.e., short-answer and yes-no) questions in each interview about activities with the man.

Interviewers were female, blind to study hypotheses, had not met the child during the play event (i.e., first session), and conducted interviews across the main experimental conditions. For children questioned repeatedly, the same interviewer conducted each interview to eliminate effects of changing interviewers on performance (e.g., Bjorklund et al., 2000; Quas \& Schaaf, 2002). During the play event and interviews, the presence of male research assistants (RAs) was prohibited in the laboratory, and no men interacted with the children. The delay between the play event and final (i.e., third or only, depending on the condition) interview was approximately 3 weeks and was comparable between children in the single ( $M$ $=21.76$ days, range $=16-30)$ and repeated $(M=23.00$ days, range $=18-32)$ interview conditions. Children were questioned in a room adjacent to the playroom and did not reenter the playroom during subsequent sessions.

All sessions were videotaped. After each session, children were given a prize. Parents received a small honorarium for their participation. Study procedures were approved by the appropriate Institutional Review Boards.

Play event-Parents who expressed interest in university research were contacted by telephone, and the study was described. A convenient time to participate was scheduled for parents who wished to take part. On arrival, a female RA explained the study to parents, obtained their written consent, and asked them to complete a questionnaire concerning the child's age, gender, and ethnic background and the parents' annual income and education. 
A second female RA established rapport with the child, obtained the child's verbal assent to participate, and administered several standardized measures (see Quas \& Schaaf, 2002). The RA then escorted the child into a room that contained crayons, paper, puppets, "magic" toys (e.g., wand, cape), stickers, and a large standing cat costume. She invited the child to color, pointed out the different toys, and referred to the cat costume as "Simon the Cat." Then, the RA excused herself to retrieve some paper. As she left, she told the child that she or he could play with anything in the room. The same toys were available to all children, and all children played with at least some toys. When a child did not voluntarily play with the toys (e.g., she or he only colored), the RA reentered after 3-5 min, again pointed out the toys, and left. After approximately $10 \mathrm{~min}$, the RA escorted the child out of the playroom. Before leaving, parents were asked not to discuss with the child between sessions.

Intervening interviews-Children in the repeated interview condition were exposed to two identical intervening interviews conducted by a biased or control interviewer. All interviewers were female and had not met the child during the play session. Interviewers began by explaining that they wanted to talk about the time the child played in the "Simon the Cat" room. A photograph of the room was presented to cue children to the specific session.

The biased interviewer then provided a series of statements and behaviors indicating she had a preconceived notion that the child had played with an adult man. Her biasing statements and behaviors occurred independent of the actual interview questions, which were identical across conditions. She began by telling the child that her or his parent said the child played with a man (named Todd or Chris, randomly distributed across study conditions). ${ }^{1}$ She specifically stated,

Your mom [dad] told me about the time you came here and played with my friend, Todd [Chris]. I'll show you a picture of him [photograph of confederate presented]. Your mom [dad] told me that you played in the magic room and that you and Todd [Chris] did a lot of fun stuff. You played with the magic cape, played with the wand, and did a lot of fun stuff, although she also said that Todd [Chris] might have done some stuff which wasn't really good.

Then, at prescribed times during the direct questions, the interviewer provided additional encouragement that explicitly mentioned playing with the man (e.g., "You're doing a great job answering these questions about the time you played with Todd [Chris]," "I just have a few more questions about the time you played with my friend Todd [Chris] in this room"). While providing the biased statements, the interviewer applied focused pressure by looking at, smiling, and leaning toward the child. The presentation of potentially false evidence, such as the photograph of the man, has been used in prior studies of children's suggestibility (Leichtman \& Ceci, 1995) and in actual forensic interviews with alleged abuse victims (e.g., Bidrose \& Goodman, 2000;Jones \& Krugman, 1986). This evidence, along with the interviewer's statements and behaviors, created the highly biased context that put pressure on children to allege that they played with the man.

In the control condition, the interviewer never mentioned that the child's parent said the child played with a man, and she began by stating that the child could say "I don't know" if the child forgot an answer. Also, at the prescribed times in the direct questions when the biased interviewer provided encouragement statements referencing the man, the control interviewer provided similar encouragement but did not mention the man (e.g., "You're doing a great job answering these questions about the time you played"). Finally, the

\footnotetext{
${ }^{1}$ The RA confirmed that the child did not have a close friend or family member named Todd [Chris] so as not to confuse the child.
} 
photograph of the man was presented in conjunction with direct questions that referenced the man (i.e., "Did you play with this man?"), but he was not named directly. Although actual questions were identical across interview conditions, the control interview context was designed to reduce pressures on children so that they felt comfortable describing their play session and refuting misleading questions.

The precise questions asked during the intervening interviews were administered in the same order for all children. First were three free-recall prompts: "I need you to tell me what happened when you played in this room" (while pointing to the photograph of the room), "I wasn't there in that room with you, so I need you to tell me everything you can remember about what happened," and "Can you remember anything else about what happened in the playroom? Tell me anything else." Next were 35 direct questions about details of the play event. Some required "yes" responses, some required "no" responses, and some required short-answer responses. Approximately half $(n=16)$ of the questions asked about the man's activities (e.g., the first question was, "Did you play with this man in this 'Simon the Cat' room?" [while the interviewer pointed to photographs of confederate and room]; other questions included, "Did the man do something yucky when you were in this room?" and "That man wore a magic cape, didn't he?"). Questions unrelated to the man included: "Were there any stickers in that room?" and "What did you color?"

During each interview, parents completed a questionnaire concerning how often they or their child had talked about prior sessions. Also, after each interview, parents were reminded to refrain from discussing the play event or interviews with their child.

Final interview-In the final interview (the only interview for children in the single interview condition), the interviewer again began with biased or control statements and behaviors, as in prior interviews. Then, to increase the ecological validity of the study and to test whether children who had been repeatedly questioned versus children who had not been repeatedly questioned by the biased interviewer would generate similar false reports specifically implicating the man, the interviewer stated, when she presented the playroom photograph, that something bad might have happened in the playroom. This mild accusation did not specifically mention the man and was provided to children across conditions.

The final interview (see the Appendix) began with three free-recall questions, identical to those asked in intervening interviews. Next were 18 direct questions. Consistent with prior studies (e.g., Leichtman \& Ceci, 1995;Melnyk \& Bruck, 2004), we varied these questions slightly from those asked in the intervening interviews. They began with the yes-no question, "Did you play with this man in that room?" while the interviewer pointed to the photographs of the confederate and room. The questions ranged in suggestiveness (e.g., some required a yes-no response, others included false suppositions); correct answers included "yes," "no," and open-ended responses; and 10 questions asked about the man's activities. The biased or control interviewer's statements of encouragement that mentioned the man or not, respectively, were delivered twice during the direct questions (the timing of these statements is noted in the Appendix). ${ }^{2}$

After the final interview, children were fully debriefed, which included providing ageappropriate corrections of errors and presenting a videotape of children's playroom activities to remind them of what had occurred during the play event. Children in the interviewer bias

\footnotetext{
${ }^{2}$ Source-monitoring questions were included at the end of the final interview. Because the precise questions asked varied depending on children's answers, these questions are not considered further (but see Quas, Schaaf, Alexander, \& Goodman, 2000, for analyses of a subset of the children's source-monitoring responses).
} 
condition were further told that the interviewer had made a mistake when she told children about their parent's statements concerning interacting with a man in the playroom. ${ }^{3}$

\section{Coding}

Children's responses were reliably scored in two categories: memory performance and false reports. For all scores, responses from $15 \%$ of the children (randomly selected across study conditions) were coded by two independent raters. Proportion agreement for free-recall was .91, and kappas for the other variables were $\geq .91$. Discrepancies were resolved through discussion.

Memory performance-Memory scores included free-recall units of correct and incorrect information and direct question proportion correct, incorrect, and do-not-know responses. For free recall, consistent with prior studies (e.g., Poole \& Lindsay, 1995; Quas $\&$ Schaaf, 2002), we coded children's narratives for units of information, defined as any piece of syntactic information corresponding to agents (who), actions (verb), objects (recipient of action), and descriptors (adjective). Children received a unit for each item provided, and the number of correct and incorrect units was summed separately. Incorrect units indexed the total amount of false narrative detail children produced, regardless of whether this detail concerned the man. For example, 1 child received three incorrect units for the statement "I fell in there" because she did not fall while in the playroom. All statements concerning the man were scored as incorrect. For instance, 1 child stated, "He helped me color the picture." Although this child had in fact colored, she received four incorrect units (one each for "he," "color," "me," and "picture") because the statement concerned behaviors of the man who was never present. Redundant information was scored once (e.g., for the statement "I played, I played with the puppets," "I played" was only scored once). Finally, children who provided no information and only said some variation of "do not know" (17.3\% of the children) or who produced an unintelligible response (5.3\%) were given scores of zero for correct and incorrect units. All children's free-recall narratives in the final interview were scored, as were the first-interview free-recall narratives for children in the repeated interview condition (these narratives were compared in a secondary set of analyses with those of children in the single interview condition to examine delay effects).

Children's responses to the direct questions were scored as correct, incorrect, do not know, or unscoreable (i.e., unintelligible, did not answer the question). Each type of response was summed and divided by the number of direct questions asked to create proportion scores. Because the questions varied in their suggestiveness and some yes-no questions asked about false details and could thus be considered leading (e.g., Scullin \& Ceci, 2001), we combined all direct questions in the proportion scores. ${ }^{4}$ When proportions were computed separately

\footnotetext{
${ }^{3}$ With one exception, children in the study readily accepted the debriefing. The exception concerned a 3-year-old who appeared to have accepted the debriefing but later, with her mother, commented that she had played with the man. The mother, in a follow-up conversation with one of the lead researchers, explained that she routinely questions her child about interacting with adult men, about bad things happening, and about touching, because the mother was sexually abused as a child. The mother further stated that she had probed the child further on hearing the statements. The researcher had follow-up phone conversations with the mother, requested that she not attempt to debrief the child and not mention the man (or any of the play session topics) again, and confirmed that the child had no associated problems. A week later, the mother stated that the child had not mentioned the man again. Although anecdotal, we suspect that the mother's personal history and past discussions with the child, combined with the mother's repeated biased probing, contributed to the child's statements. Such evidence highlights the potentially dramatic results of different sources of influence on children's reports (see Bruck, Ceci, \& Principe, 2006). This child's responses also reveal the need for clear and detailed debriefing protocols and well-outlined follow-up procedures should a child resist debriefing at any time.

${ }^{4}$ Two questions were excluded from the proportion computations: "What games did you play in this room?" and "What did you do with the puppets?" because children's answers suggested that they misinterpreted the questions (e.g., thought games referred to board games) or contained both correct and incorrect information (e.g., "I played with the mouse and lamb puppet" when the child only played with the mouse), precluding us from classifying their answer as correct or incorrect.
} 
for specific and misleading questions, scores were highly correlated $(r s>.59)$, and findings were similar across measures. Unscorable responses constituted .04 of children's answers to the direct questions and are not considered further. As in previous research (e.g., Leichtman \& Ceci, 1995; Melnyk \& Bruck, 2004), direct questions in the final interview varied from those asked in the intervening interviews (seven questions were identical across interviews, but the order in which these questions were asked varied). As such, it was not appropriate to compare direct question performance across interviews among children repeatedly interviewed.

False reports-Two scores were computed to identify children who specifically indicated that that they had interacted with the man. A dichotomous variable, termed free-recall false implication, indicated whether (1) or not (0) children implied that they had interacted with Todd (Chris). Specifically, children received a yes score (1) if their free-recall narratives ever implied the man's presence in the playroom. Examples of statements coded as "implied the man was present" included: "I think he took off some of the stickers. Todd, I think" and "He was kind of funny too." The false implication score was calculated for all children's final interview narratives and the first interview narratives for children in the repeated interview condition. Coders obtained $100 \%$ agreement in scoring this variable.

The number of direct questions asked before children, in their responses, implied that they had interacted with the man was counted to create a direct question resistance score. Low scores indicate little resistance to suggestion (i.e., assenting to having played with the man early in the direct questioning portion of the interview), and high scores indicate greater resistance. For example, in response to the 11th question, "Who was in this room when you played in there?," 1 child, who had not made any statements about the man until this point, said "a man." This child thus received a score of 11. In response to the 6th question, "Did the man do something yucky when you were in this room?," another child said, "He was getting a slug," and thus received a score of 6 . Although this child had answered other direct questions incorrectly, she had not, until this question, implied in her answers that the man had been present. Thus, scores do not necessarily indicate that children made no errors prior to that question. Instead, children's prior answers did not imply that the man had been present. Resistance scores were computed independently of the free-recall false implication scores. Children who never implied that they interacted with the man when answering the direct questions $(n=16)$ received a score of 17 , one greater than the number of direct questions asked.

\section{Results}

Preliminary analyses tested for confounds. The main analyses assessed effects of repeated interviews versus interviewer bias on children's memory and false reports in the final interview. Separate analyses examined delay and interviewer bias effects.

\section{Preliminary Analyses}

Potential confounds included children's gender and age, family socioeconomic status, and the delay between the play session and final interview. The $t$ tests revealed no significant gender differences in performance. Two separate 2 (interview repetition: single vs. repeated) $\times 2$ (interviewer bias: biased vs. control) analyses of variance (ANOVAs) predicting child age in months were conducted, one with 3-year-olds and one with 5-year-olds. Children's age in months was equivalent across conditions. No significant correlations emerged between family socioeconomic status (according to parents' scaled responses, with 1 [less than \$15,000 annual income] and 6 [over \$90,000 annual income]) and children's memory or false report scores, and family socioeconomic status did not vary across conditions, as 
indicated by ANOVAs. Finally, a 2 (age) $\times 2$ (interview repetition) $\times 2$ (interviewer bias) between-subjects ANOVA revealed that the delay (in days) between children's play session and final interview was comparable across conditions.

\section{Interview Repetition and Interviewer Bias}

The main goal of this study was to investigate the effects of repeated interviews and interviewer bias on children's memory and false reports. Of particular interest was whether these manipulations differentially affected 3- and 5-year-olds' proneness to false claims of interacting with an adult man. Unless otherwise noted, scores were entered into 2 (age) $\times 2$ (interview repetition) $\times 2$ (interviewer bias) between-subjects ANOVAs.

Memory performance-Five scores reflected children's memory performance in the final interview: (a) free-recall units of correct and incorrect information provided and (b) the proportion correct, incorrect, and do-not-know responses to direct questions.

When we examined children's free-recall units of correct information, no significant effects emerged, although the age and interviewer bias effects both approached significance, $F \mathrm{~s}(1$, $67) \geq 3.34$, $p$ s $<.08$ (see Table 1). More robust findings emerged when we examined children's free-recall units of incorrect information. Significant main effects of interview repetition $(M \mathrm{~s}=2.84$ and 0.74 for children in the single and repeated interview conditions, respectively) and interviewer bias, $F \mathrm{~s}(1,67) \geq 4.86, p \mathrm{~s}<.05, \eta^{2}>.07$, emerged but were qualified by a significant Interview Repetition $\times$ Interviewer Bias interaction, $F(1,67)=$ $5.79, p<.05, \eta^{2}=.08$. Follow-up planned comparisons revealed that children questioned only once by the biased interviewer provided significantly more incorrect information than did children questioned only once by the control interviewer and than children questioned repeatedly by the biased or control interviewer, $t \mathrm{~s} \geq 3.16, p s<.01$ ( $d f \mathrm{~s}=35$ and 37 , respectively). Children in the latter three conditions did not significantly differ and in fact provided little false narrative detail (see Table 1). ${ }^{5}$

Next, children's correct, incorrect, and do-not-know responses to direct questions were examined (see Table 1). Children's proportion scores (the number of each type of responses divided by the number of direct questions asked) were subjected to separate 2 (age) $\times 2$ (interview repetition) $\times 2$ (interviewer bias) ANOVAs. For correct responses, significant main effects of age, $F(1,67)=22.65, \eta^{2}=.25$, and interview repetition, $F(1,67)=16.89, \eta^{2}$ $=.20, p$ s <.001, emerged: 5 -year-olds provided a greater proportion of correct responses than did 3-year-olds ( $M s=0.82$ and 0.56 , respectively). Also, children interviewed repeatedly provided a greater proportion of correct responses than children interviewed only once ( $M s=0.72$ and 0.57 , respectively).

For incorrect responses, a significant main effect of age, $F(1,67)=37.15, \eta^{2}=.36$, revealed, as expected, that the 5-year-olds provided relatively few incorrect responses, that is, were less suggestible, than did the 3-year-olds ( $M s=0.14$ and 0.32 , respectively). Also, a significant main effect of interview repetition emerged, $F(1,67)=14.96, \eta^{2}=.18(M \mathrm{~s}=$

\footnotetext{
5 In a separate analysis, we computed proportion scores to reflect the amount of correct information children provided in their freerecall narratives relative to the total amount of information they provided and subjected these scores to a 2 (age) $\times 2$ (interview repetition) $\times 2$ (interviewer bias) ANOVA. The sample size decreased slightly because children who provided no correct or incorrect information (e.g., who only said "do not know" in free recall) were not included. (These children received scores of zero for both correct and incorrect free-recall units, and it is not possible to divide scores by zero. Also, the meaning of a zero proportion for these children in this analysis is ambiguous). A significant main effect of interviewer bias, $F(1,59)=5.46, p<.05$, revealed that children questioned by the biased interviewer provided a lower proportion of correct information in their narratives $(M=0.68)$ than did children questioned by the control interviewer $(M=0.89)$. The Interview Repetition $\times$ Interviewer Bias interaction approached significance, $F(1,59)=3.04, p<.10$. Means for the four conditions were as follows: single interview, biased interviewer: $M=0.55$; single interview, control interviewer, $M=0.90$; repeated interview, biased interviewer: $M=0.81$; repeated interview, control interviewer: $M=0.87$.
} 
0.29 and 0.18 for the single and repeated interview conditions, respectively) but was qualified by a significant Interview Repetition $\times$ Interviewer Bias interaction, $F(1,67)=$ $8.76, \eta^{2}=.12, p s<.01$. According to follow-up planned comparisons, although children interviewed once appeared to be more inaccurate than were children interviewed repeatedly, this pattern primarily was due to poor performance among children interviewed once in a highly leading manner (i.e., by the biased interviewer; see Table 1). These children provided a greater proportion of incorrect responses than did the other children, $t \mathrm{~s}>3.96, p \mathrm{~s}<.001$ $(d f \mathrm{~s}=35-37)$. The proportion incorrect scores of children interviewed once by the control interviewer did not differ significantly from the scores of children interviewed repeatedly by the biased or control interviewer.

Finally, for do-not-know responses, the main effect of age was significant, $F(1,67)=9.33, p$ $<.001, \eta^{2}=.12$, and the main effect of interviewer bias approached significance, $F(1,67)=$ $3.67, p=.06, \eta^{2}=.05$. When answering the direct, including misleading, questions, the older children $(M=0.11)$ provided a greater proportion of do-not-know responses than did younger children $(M=0.05)$. Also, children questioned by the control interviewer were slightly more likely to respond "do not know" than were children questioned by the biased interviewer (see Table 1).

It was theoretically possible that interview repetition primarily affected children's accuracy, whereas interviewer bias primarily affected children's errors and suggestibility (Brainerd \& Ornstein, 1991; Melnyk \& Bruck, 2004). To examine this possibility, we divided the final interview direct questions into those concerning true details (e.g., the child's activities and room) and those concerning false details (e.g., the children's alleged interaction with the man; see the Appendix). We then created separate correct and incorrect proportion scores for the two types of questions and subjected these proportion scores to 2 (age) $\times 2$ (interview repetition) $\times 2$ (interviewer bias) ANOVAs.

When children's true detail correct proportion scores were considered, significant main effects of age and interview repetition, $F \mathrm{~s}(1,67) \geq 3.84, p s \leq .05, \eta^{2} \geq .05$, were qualified by significant Age $\times$ Interviewer Bias and Interview Repetition $\times$ Interviewer Bias interactions, $F \mathrm{~s}(1,67) \geq 4.04, p \mathrm{~s}<.05, \eta^{2} \geq .06$. The Age $\times$ Interviewer Bias interaction suggested that older children $(M=0.79)$ were more accurate than younger children $(M=$ $0.54)$ when asked about true details by the control interviewer. Older $(M=0.68)$ and younger $(M=0.69)$ children did not differ, however, when questioned by the biased interviewer. The Interview Repetition $\times$ Interviewer Bias interaction suggested that, in the biased interviewer condition, children interviewed repeatedly $(M=0.76)$ were more accurate than were children interviewed once $(M=0.60)$. In the control condition, repetition did not significantly affect performance $(M \mathrm{~s}=0.68$ and 0.65 for the repeated vs. single interview conditions, respectively). Next, children's true detail incorrect proportion scores were examined. Older children provided fewer errors than did younger children, $F(1,67)=4.33$, $p<.05, \eta^{2}=.06$. A significant Age $\times$ Interview Repetition interaction, $F(1,67)=5.57, p<$. $05, \eta^{2}=.08$, indicated that repetition benefited older but not younger children in terms of reducing errors $(M \mathrm{~s}=0.27$ and 0.09 for 5-year-olds questioned once vs. repeatedly; $M \mathrm{~s}=$ 0.26 and 0.29 for 3 -year-olds questioned once vs. repeatedly).

Next children's false detail proportion correct and incorrect scores were analyzed. Robust significant effects of age and interview repetition emerged, $F \mathrm{~s}(1,67)>15.26, p \mathrm{~s}<.001, \eta^{2}$ $>.19$. Older children were more accurate $(M=0.76)$ and made fewer errors $(M=0.08)$ to direct questions about the man's activities than did younger children $(M \mathrm{~s}=0.57$ and 0.31 , respectively). Also, children interviewed repeatedly were more accurate $(M=0.75)$ and made fewer errors $(M=0.12)$ than children interviewed only once $(M \mathrm{~s}=0.57$ and 0.27 , respectively). For incorrect proportions, a significant Interview Repetition $\times$ Interviewer 
Bias interaction also emerged, $F(1,67)=6.37, p<.01, \eta^{2}=.09$. The beneficial effects of repetition (here in relation to reducing errors to questions about the man) emerged when the interviewer was biased ( $M \mathrm{~s}=0.35$ and 0.10 for children interviewed once vs. repeatedly) much more than when the interviewer was not biased $(M \mathrm{~s}=0.19$ and 0.14 for children interviewed once vs. repeatedly). These findings are consistent with the true detail analyses presented previously. Thus, when we heuristically divided direct questions into those that probed for true versus false details, differential associations of repetition and bias with accuracy versus errors did not emerge. This finding argues against the idea that interview repetition primarily affected accuracy and that interviewer bias primarily affected errors. Instead, repetition appeared to serve as a memory buffer across both question types, particularly among the older children and among children exposed to the highly biased interviewer. However, the direct questions were not specifically designed to be comparable between true and false details, and the questions were not counterbalanced across the two types of details. Thus, further research on this issue is needed.

To summarize, analyses of the memory measures revealed, as expected, clear age-related improvements in performance: Older preschoolers provided more correct and do-not-know responses and fewer suggested responses to direct questions. Also, although both interview repetition and interviewer bias affected children's memory, the effects were not entirely in the predicted directions. In free recall, children questioned only once by the highly biased interviewer, who explicitly told the children that they had played with the man, provided a greater amount of false information than did all other children. In response to the direct questions, children questioned only once, and again especially by the highly biased interviewer, were more inaccurate, providing fewer correct and more incorrect responses.

False reports-Although the aforementioned analyses revealed age, interview repetition, and interviewer bias effects on children's memory, the analyses did not provide insight into whether children specifically claimed, falsely, that they had interacted with the man. Two additional dependent measures concerned false reports regarding the man. The dichotomous false implication score indicated whether $(1=$ yes, $0=$ no $)$ at any point in response to the final interview free-recall questions, the child provided a response that implied interacting with the man. The resistance score reflected how well the child resisted, when answering each of the final interview direct questions, implying that the man had been present in the playroom (scores ranged from 1 to 17 , with higher values indicating greater resistance).

With regard to the dichotomous free-recall false implication score, irrespective of children's age or the number of interviews completed, none of the children in the control condition (i.e., those not exposed to the biased interviewer) ever implied that they had interacted with the man. This pattern emerged despite some children having completed two prior interviews in which numerous direct, including misleading, questions suggested that children had interacted with him (e.g., "Where did the man touch you?"). Thus, among children repeatedly interviewed, those questioned by the control interviewer did not incorporate false information specifically about the man from the prior interviews into their subsequent narratives.

Because no child in the control interviewer condition falsely assented in free recall to having interacted with the man, the dichotomous free-recall false implication score was entered into a 2 (age) $\times 2$ (interview repetition) ANOVA including only children exposed to the biased interviewer. The main effects of interview repetition and the Age $\times$ Interview Repetition interaction were both significant, $F \mathrm{~s}(1,33) \geq 5.08, p s<.05, \eta^{2} \geq .15$ (see Table 2).

Although children interviewed once (32\%) were generally more likely to imply that the man was present in their play session than were children interviewed repeatedly (11\%), this pattern was driven by especially poor performance among the 5- rather than the 3 -year-olds. 
Among 3-year-olds questioned by the biased interviewer, $10 \%$ of those questioned once and $10 \%$ of those questioned repeatedly falsely implied that the man was present. Among 5year-olds questioned by the biased interviewer, $56 \%$ of those questioned once implied that the man was present, whereas none of those questioned repeatedly did so. The $t$ tests (conducted because of the floor effect) confirmed the significant pairwise comparisons between 5-year-olds in the single interview, biased interviewer condition and both groups of 3 -year-olds (i.e., those in the single or repeated interview, biased interviewer conditions), $t \mathrm{~s}$ $=2.87, p \mathrm{~s} \leq .01, d f \mathrm{~s}=17$.

Next, the direct question resistance measure was entered into a 2 (age) $\times 2$ (interview repetition) $\times 2$ (interviewer bias) ANOVA. Significant main effects of age, $F(1,67)=18.84$, $\eta^{2}=.22$, interview repetition, $F(1,67)=12.33, \eta^{2}=.16$, and interviewer bias, $F(1,67)=$ $10.54, \eta^{2}=.14$, emerged $(p s<.001)$. Three-year-olds $(M=6.42)$ were less resistant (i.e., assented to interacting with the man after fewer direct questions) than were 5-year-olds ( $M=$ 14.89). Children exposed to the biased interviewer were less resistant than were children exposed to the control interviewer (see Table 2). Finally, children interviewed once ( $M=$ 7.00) were less resistant than were children interviewed repeatedly $(M=11.34)$.

In summary, none of the children questioned by the control interviewer implied in their freerecall narratives that they had interacted with the man during the play session. In other words, no child made a false alarm about the man without first being exposed to the biased interviewer who explicitly stated that such an interaction had occurred. This pattern emerged despite half of the children questioned by the control interviewer having been exposed to two prior interviews that contained several misleading questions implying the man was present. Surprisingly, among children questioned by the biased interviewer, 5-year-olds questioned only once were more likely to imply in free recall that they had interacted with the man than were other children. The more common and expected age-related decreases in errors emerged when children's resistance during the direct questions was considered: The 3 -year-olds assented more quickly than did 5-year-olds to having interacted with the man. Finally, children exposed to the biased interviewer and children interviewed once assented more quickly during the direct questions to the man's presence than did children exposed to the control interviewer and children questioned repeatedly.

\section{Effects of Delay and Interviewer Bias}

The aforementioned analyses indicate that children questioned once rather than repeatedly by the highly biased interviewer were more inaccurate and were more susceptible to falsely reporting having interacted with the man. A logical interpretation of this pattern is that the longer delay between the play session and first exposure to the biased interviewer for children questioned once led to their increased forgetting and greater susceptibility to the interviewer's false suggestions. Among children questioned repeatedly, even when the interviewer was highly biased, the first interview took place only 1 week after the original play session. The relatively short delay may have enabled children to reinstate their original memory representation, leading to reduced forgetting and a continued ability to maintain accuracy in the final interview, even in the face of misleading questions and a biased interviewer putting pressure on them.

The design of our study enabled us to test this interpretation. Because the free-recall prompts were identical across interviews, we conducted a second set of analyses comparing freerecall narratives between children first interviewed 1 week after the play session (which corresponds to the first interview for children in the repeated interview condition) and children first interviewed 3 weeks after the play session. In other words, the two "repeated" groups in our study design were replaced by two "delay" groups: short (1 week) and long (3 weeks). The effects of delay, in conjunction with children's age and interviewer bias, were 
then examined in 2 (age) $\times 2$ (interviewer bias) $\times 2$ (delay: short vs. long) ANOVAs. Because children in the long delay condition here correspond to children in the single interview condition in the aforementioned analyses, the means reported in Table 3 are identical to their means according to Tables 1 and 2 .

First, the free-recall units of correct and incorrect information were entered into separate 2 (age) $\times 2$ (interviewer bias) $\times 2$ (delay) ANOVAs. For correct units of information, no significant effects emerged. For incorrect units, significant main effects of interviewer bias, $F(1,67)=8.80, \eta^{2}=.12$, and delay, $F(1,67)=6.45, \eta^{2}=.09$, were subsumed by a significant Interviewer Bias $\times$ Delay Interaction, $F(1,67)=6.66, \eta^{2}=.09, p \mathrm{~s}<.05$. Planned comparisons indeed revealed that children interviewed by the highly biased interviewer after a 3-week delay provided a greater amount of incorrect information in their free-recall reports than did children interviewed by the control interviewer after a 3-week delay and children interviewed after a 1-week delay, $t \mathrm{~s} \geq 3.49, p s<.01(d f \mathrm{~s}=35-37)$, regardless of whether the latter children were exposed to the biased or control interviewer (see Table 3).

We next examined the dichotomous free-recall false implication score. Consistent with the previous analyses, none of the children questioned by the control interviewer, regardless of whether the interview took place after a 1- or 3-week delay, implied that the man was present. A 2 (age) $\times 2$ (delay) ANOVA was thus conducted among only children in the biased interviewer condition. The Age $\times$ Delay interaction was significant, $F(1,33)=6.89$, $p<.05, \eta^{2}=.17$. Five-year-olds questioned the first time 3 weeks after their play session took place were substantially more likely to imply in free recall that they had interacted with the man $(56 \%)$ than were the other children (Table 3). In fact, none of the 5-year-olds questioned after only a 1-week delay by the biased interviewer made such an implication, and $10 \%$ of the 3 -year-olds interviewed after the 3 -week delay and $20 \%$ of the 3 -year-olds interviewed after a 1-week delay did so. The $t$ tests, conducted because of the floor effect, again confirmed the significant pair-wise differences suggested by the ANOVA. The mean for 5-year-olds questioned by the biased interviewer after the long delay was significantly greater than was the mean for 3-year-olds questioned by the biased interviewer after both the short and long delay, $t \mathrm{~s} \geq 2.07, p \mathrm{~s} \leq .05, d f \mathrm{~s}=17$.

These analyses confirmed that the especially poor performance among children interviewed only once by the biased interviewer likely was due to the longer delay between their play event and first interview relative to the delay between the play event and first interview for children repeatedly interviewed. Specifically, children exposed to the biased interviewer after a long delay were more inaccurate in free recall and were more likely to falsely imply that they had played with the man than were the other children. Errors were particularly robust in the older relative to the younger children, perhaps because of the older children's greater willingness (or ability) to provide narrative accounts, narratives that unfortunately included false details about the man.

\section{Discussion}

The overarching goal of our study was to investigate developmental differences in the effects of repeated interviews and interviewer bias on children's memory and false reports. Interview repetition did not increase children's errors, even though each interview contained misleading questions and, for half of the children, began with an interviewer providing highly biased statements. In contrast, when the first interview took place 3 weeks after the original event, the effects of the highly biased interviewer were particularly deleterious. Finally, several age-related improvements in performance emerged, although notably so did a few reverse age effects, whereby older children were more likely to provide false information. Next, we turn to an in-depth interpretation of these three patterns of results. 
First, with regard to repeated interviews, varying results across former studies concerning interview repetition have been difficult to reconcile because of the different types of to-beremembered events examined, methodologies used, and ages included. Our findings reveal that an inoculation effect is likely when children are asked direct questions about an event that occurred relatively recently. Specifically, compared with children interviewed once 3 weeks after their original play event, children interviewed repeatedly beginning 1 week after their original play event provided a greater proportion of correct responses and were more resistant to implying falsely that they had interacted with the man. Of note, children in the repeated interview condition were still familiar with false information about the man-they had been exposed, in two intervening sessions, to misleading questions about him, and half of these children were questioned each time by the biased interviewer who explicitly said that they had interacted with the man. Yet, source-monitoring failure did not occur. Instead, few children in the repeated interview condition and none questioned by the control interviewer provided any information in their final interview free-recall reports indicating that they had played with him.

The at-times superior performance of children exposed to repeated interviews relative to a single interview likely was due to the intervening interviews serving as reminder cues. Children rehearsed the event each week, which may have consolidated their memory (Schneider, 2002) and led to a stronger gist memory trace, which may have reduced their susceptibility to pressure from the biased interviewer and to suggestions that may have tapped verbatim memory. Also, children may have learned over time that the interviewer makes mistakes, reducing their trust in her statements (Welch-Ross, 1999). Finally, to the extent that the false suggestions were blatantly incorrect (Loftus, 1979), they may have alerted children to be cautious of the interviewer's statements and questions. Evidence indicates that even preschool-age children are cognizant of and alter their interactions with adults who provide clearly inaccurate statements (e.g., Clement et al., 2004; Koenig \& Harris, 2005). With their relatively strong memory trace, children repeatedly interviewed about the false interaction may have easily recognized the interviewer's inaccuracies, leading them simply to ignore the interviewer's biased statements (Koenig \& Harris, 2005). Of course, our study is not the first to report greater accuracy among children repeatedly rather than singly interviewed (see Ornstein et al., 1997). However, our study is one of the first to demonstrate that repeated interviews about a false event, in this case, an interaction with an adult man that never took place, do not necessarily increase children's propensity to err. Of course, had multiple interviews taken place after an even longer delay, children may have been more willing to claim that the false interaction occurred. However, at least under the circumstances of our study, repeated interviews about a false event, even with the inclusion of misleading questions, did not adversely affect children's performance relative to the performance of children exposed to a single interview that occurred following a comparable delay.

Second, we found strong evidence for adverse effects of interviewer bias on children's performance. This was especially true in the single interview condition. In other words, children first questioned by a highly biased interviewer 3 weeks after their play session took place were the most inaccurate. The children's errors emerged early in the interview, specifically in their free-recall responses and then again in their direct question responses. Although free recall is typically considered highly accurate, our findings indicate that, under certain conditions, even children's free-recall reports can contain dramatic inaccuracies (see Poole \& Lindsay, 2002), inaccuracies that include implying an entirely false social interaction took place. Moreover, interviewer bias effects are not confined to young preschoolers. At times, older children may actually be more susceptible to such pressures, at least when inaccuracies in free recall are examined (see Ceci, Kulkofsky, Klemfuss, Sweeney, \& Bruck, in press, for an extended discussion of this issue). 
Of importance, our secondary analyses of all children's first interview performance revealed that the deleterious effects of interviewer bias primarily emerged when there was a longer rather than a shorter delay between the to-be-remembered event and the interview. At the start of the final interview for children in the long delay condition (both in the biased and control interviewer conditions), the interviewer stated that something bad might have happened. Although this statement could have contributed to some slight differences in accuracy between children in the short delay and long delay conditions, it is unlikely that this statement was sufficient to lead to the dramatic differences in performance we observed. Had the statement been crucial, children in the repeated interview, control interviewer condition should also have evidenced a greater number of errors in their final interview, which did not occur. Instead, we suspect that, when only 1 week had passed since the play event, the children's memory traces were strong enough that they were able to refute the biased interviewer's false suggestions. However, when 3 weeks had passed since the play event without any intervening sessions, children's memory had faded. They may then have been confused about what actually occurred during the play session versus the immediate information provided by the biased interviewer, leading to source-monitoring failure (see Roberts \& Blades, 2000). Alternatively, at the later time, children may have gone along with the interviewer's suggestions because of their greater confidence in the adult's rather than their own memory.

Third, several important age differences emerged. Most were in the expected direction, consistent with previous studies (e.g., Baker-Ward et al., 1993; Leichtman \& Ceci, 1995; Poole \& Lindsay, 2001): Compared with 3-year-olds, 5-year-olds were more accurate when answering the direct questions and were more resistant, during the direct questioning, to implying that they played with the man. Yet, one finding was in the opposite direction: In free recall, 5-year-olds in the single interview condition questioned by the biased interviewer were more likely than were 3-year-olds similarly questioned to claim that they had interacted with the man. This particularly poor free-recall performance among 5-year-olds in the single, biased interviewer condition likely is due to a number of factors. For one, with age, the amount of information children provide about prior experiences increases (e.g., Fivush \& Haden, 1997; Fivush et al., 2004; Goodman, Quas, Batterman-Faunce, Riddlesberger, \& Kuhn, 1997). Also, with age, children have a better understanding of conversational rules and may be more sensitive to others' expectations of children during an interview (Carter, Bottoms, \& Levine, 1996; Cordon, Goodman, \& Saetermoe, 2005). The 5 -year-olds questioned after a long delay may also have been cognizant of their limited memory, leading them to rely on the interviewer for additional event information for inclusion in their narratives. Each of these could increase older children's errors. A few other studies have similarly found that, at times, age predicts greater rather than reduced suggestibility, in large part because of age-related increases in children's pragmatic or semantic knowledge (e.g., Ceci, Papierno, \& Kulkofsky, in press; Scullin \& Ceci, 2001; see also Ceci, Kulkofsky, et al., in press). Thus, although perhaps surprising at face value, converging evidence highlights that there are certain conditions under which older children are at increased risk for errors.

Of note, despite the larger proportion of these 5-year-olds falsely assenting in free recall to interacting with the man, the 5-year-olds were more resistant when answering the direct questions than were 3-year-olds to assenting to having played with him. Thus, it is unlikely that the 5-year-olds had developed a false representation or "memory" of the interaction. Instead, they appeared to be more sensitive to the demands of the interview and to their own memory limitations, which, when combined with their greater pragmatic knowledge, led to their errors in free recall. 
Although the present study provides new insight into developmental changes in the effects of repeated interviews and interviewer bias on children's event reports, caveats must also be mentioned, most notably regarding the generalizability of the results. First, despite the children in this study being questioned about a false interaction with a man, the children had experienced some sort of event, in this case a play session, albeit alone. Thus, the children had an original event representation on which they could rely when answering questions and to which they could compare the interviewer's suggestions. In several former false event studies, there was no original to-be-remembered event (e.g., Bruck et al., 2002; Ceci, Loftus, et al., 1994). Thus, there was no delay between the to-be-remembered event and the memory interview that could be examined in relation to children's exposure to repeated interviews and interviewer bias.

Second, in the current study, children in the repeated interview condition were questioned three times about an event that they allegedly personally experienced, and the first interview took place 1 week after the original event. The timing of the interviews, the content of the to-be-remembered event, and the number of interviews all likely affected the pattern of results obtained. Had the first of several interviews taken place after a substantially longer delay, more children may have begun to err, possibly even those who had not been questioned by the biased interviewer. Children may also have been more prone to err if they had been asked about a false witnessed event rather than a false experienced event, consistent with research indicating that children are less resistant to suggestions about witnessed than experienced events (Tobey \& Goodman, 1992). Also, although some studies have included fewer interviews and observed high false report rates, even in an initial interview (e.g., Bruck et al., 2002; Garven et al., 1998; Quas et al., 1999; Thompson et al., 1997), other studies have exposed children up to a dozen interviews about fictitious events (e.g., Ceci, Huffman, et al., 1994). Had more interviews been included, the number of children claiming that the interaction occurred may have increased. Anecdotally, however, several children appeared tired of answering the interviewer's questions by the third interview. Had we attempted to interview these children several more times, we suspect that they would simply have refused to answer questions rather than state that they played with the man. Of course, if, as conducted in some prior studies (e.g., Ceci, Loftus, et al., 1994), we structured the interview as a game rather than as a memory test, the children may have been more interested in continuing to answer questions.

Third, it is possible that the inclusion of the photographs during the memory interview(s) or children's experiences between sessions affected their performance. However, the photographs did not contain temporal markers or details about specific activities associated with the original event. Also, the photographs were presented to all children, across conditions and thus did not differentially affect children's memory. Additionally, the photographs differed in whether they represented true (i.e., the "Simon the Cat" room) versus false (i.e., Todd [Chris]) information, making it difficult to determine the precise direction of the photographs' effects. Also, the presentation of reminder cues, including false cues, is a technique used in former studies of children's false memory (e.g., Leichtman \& Ceci, 1995; Poole \& Lindsay, 1995, 2001). Finally, children's memory may have been affected by rehearsing details of the event through conversations with other individuals between the sessions. However, parents rarely reported that they, their child, or other individuals talked about the play event or interviews. It is impossible to verify whether parents were truthful in their reports of such conversations. Nonetheless, parental report is often relied on in studies involving preschool children, including other investigations of repeated interviews and parental discussions between sessions (e.g., Baker-Ward et al., 1993). 
Fourth, the fact that we combined the direct questions into a single measure deserves mention. Our direct questions included those phrased in a yes-no format (e.g., "Did you color a picture by yourself?") and those phrased in an open-ended format (e.g., "Why did the man get in trouble?"). Moreover, some included false suppositions or tags that implied particular responses (labeled misleading; e.g., “That man wore a magic cape, didn't he?"). Analyses of the specific and misleading questions separately did not yield differential patterns of results, and results did not differ when we examined performance to questions about true details and false details separately (the latter of which could all be considered "leading" because they asked about false information). Researchers have varied in their definitions of specific, nonleading, misleading, and suggestive questions (e.g., see Davis \& Bottoms, 2002; Goodman et al., 1997; Scullin \& Ceci, 2001; Sternberg, Lamb, Orbach, \& Esplin, 2001), and certainly these differences should be considered when comparing results across studies.

In closing, the overarching purpose of our study was to disentangle the effects of repeated interviews and interviewer bias on children's memory, suggestibility, and false reports. Our findings do not lead to a general conclusion that there is no harm in repeated interviews, and our findings are not applicable to all legal cases involving child witnesses and multiple interviews. We did not test many of the factors potentially operative in a given legal case, and our results may be relevant only to cases that have relatively similar delays, interviewer statements, and number of interviews. Nonetheless, our findings do underscore two important conclusions: First, repeated interviews do not necessarily increase inaccuracies and cause false reports, even in preschool children. Instead, an inoculation effect may apply to some situations in which children are repeatedly interviewed about false events, even by biased interviewers. Second, when long delays have passed, the effects of interviewer bias are particularly deleterious, leading at times to higher numbers of older rather than younger preschoolers alleging false events occurred. Given that many forensic interviews with children occur after long delays, it is thus critical that interviewers try to adhere to appropriate interviewing techniques and best-practice guidelines (e.g., Poole \& Lamb, 1998; Sternberg et al., 2001), all of which recommend avoiding use of biased statements and misleading questions when interviewing child witnesses.

\section{Acknowledgments}

Funding for the study was obtained from the Judicial Council of California, Administrative Office of the Courts and from the School of Social Ecology at the University of California, Irvine. The opinions, findings, conclusions, and recommendations expressed in this article are those of the authors and do not necessarily reflect the views of the funders. We thank K. Alison Clarke-Stewart and William Thompson for their feedback on the manuscript, Nathalie Carrick and many undergraduate research assistants for their help with data collection, and the families who took part in the project.

\section{References}

Baker-Ward L, Gordon BN, Ornstein PA, Larus DM, Clubb PA. Young children's long-term retention of a pediatric examination. Child Development 1993;64:1519-1533. [PubMed: 8222886]

Baker-Ward L, Hess TM, Flannagan DA. The effects of involvement on children's memory for events. Cognitive Development 1990;5:55-69.

Bidrose S, Goodman GS. Testimony and evidence: A scientific case study of memory for child sexual abuse. Applied Cognitive Psychology 2000;14:197-213.

Bjorklund DF, Cassel WS, Bjorklund BR, Brown RD, Park CL, Ernst K, Owen FA. Social demand characteristics in children's and adults' eyewitness memory and suggestibility: The effect of different interviewers on free recall and recognition. Applied Cognitive Psychology 2000;14:421433. 
Brainerd, CJ.; Ornstein, PA. Children's memory for witnessed events: The developmental backdrop. In: Doris, J., editor. The suggestibility of children's recollections. Washington, DC: American Psychological Association; 1991. p. 10-20.

Brainerd CJ, Reyna VF. Gist is the grist: Fuzzy-trace theory and the new intuitionism. Developmental Review 1990;10:3-47.

Brainerd CJ, Reyna VF. Mere memory testing creates false memories in children. Developmental Psychology 1996;32:467-478.

Brainerd CJ, Reyna VF. Fuzzy-trace theory and children's false memories. Journal of Experimental Child Psychology 1998;71:81-129. [PubMed: 9843617]

Bright-Paul A, Jarrold C, Wright DB. Age-appropriate cues facilitate source-monitoring and reduce suggestibility in 3- to 7-year-olds. Cognitive Development 2005;20:1-18.

Bruck M, Ceci SJ, Hembrooke H. The nature of children's true and false narratives. Developmental Review 2002;22:520-554.

Bruck, M.; Ceci, SJ.; Principe, GF. The child and the law. In: Renninger, KA.; Sigel, IE.; Damon, W.; Lerner, RM., editors. Handbook of child psychology. 6th ed.. Vol. Vol. 4. Hoboken, NJ: Wiley; 2006. p. 776-816.

Carter CA, Bottoms BL, Levine M. Linguistic and socioemotional influences on the accuracy of children's reports. Law \& Human Behavior 1996;20:335-358.

Ceci, SJ.; Bruck, M. Children's testimony: Applied and basic issues. In: Damon, W.; Sigel, IE.; Renninger, KA., editors. Handbook of child psychology. 5th ed.. Vol. Vol. 4. New York: Wiley; 1998. p. 713-773.

Ceci SJ, Huffman MLC, Smith E, Loftus EF. Repeatedly thinking about a non-event: Source misattributions among preschoolers. Consciousness \& Cognition 1994;3:388-407.

Ceci SJ, Kulkofsky S, Klemfuss JZ, Sweeney SD, Bruck M. Unwarranted assumptions about children's testimonial accuracy. Annual Review of Clinical Psychology. in press.

Ceci SJ, Loftus EF, Leichtman MD, Bruck M. The possible role of source misattributions in the creation of false beliefs among preschoolers. International Journal of Clinical and Experimental Hypnosis 1994;42:304-320. [PubMed: 7960288]

Ceci SJ, Papierno PB, Kulkofsky S. Representational constraints on children's suggestibility. Psychological Science. in press.

Clement F, Koenig MA, Harris PL. The ontogenesis of trust. Mind and Language 2004;19:360-379.

Cordon I, Goodman GS, Saetermoe C. Facilitating children's accurate responses: Conversational rules and interview style. Applied Cognitive Psychology 2005;19:249-266.

Davis SL, Bottoms BL. Effects of social support on children's eyewitness reports: A test of the underlying mechanism. Law and Human Behavior 2002;26:185-215. [PubMed: 11985298]

Erdelyi MH, Becker J. Hypermnesia for pictures: Incremental memory for pictures but not words in multiple recall trials. Cognitive Psychology 1974;6:159-171.

Fivush, R.; Haden, CA. Narrating and representing experience: Preschooler's developing autobiographical accounts. In: van den Broek, PW.; Bauer, PJ.; Bourg, T., editors. Developmental spans in event comprehension and representation: Bridging fictional and actual events. Hillsdale, NJ: Erlbaum; 1997. 169-108

Fivush R, Sales JM, Goldberg A, Bahrick L, Parker J. Weathering the storm: Children's long-term recall of Hurricane Andrew. Memory 2004;12:104-118. [PubMed: 15098624]

Fivush R, Schwarzmueller A. Say it once again: Effects of repeated questions on children's event recall. Journal of Traumatic Stress 1995;8:555-580. [PubMed: 8564273]

Garven S, Wood JM, Malpass RS, Shaw JS III. More than suggestion: The effect of interviewing techniques from the McMartin preschool case. Journal of Applied Psychology 1998;93:347-359. [PubMed: 9648524]

Goodman GS, Bottoms BL, Schwartz-Kenney BM, Rudy L. Children's testimony about a stressful event: Improving children's reports. Journal of Narrative \& Life History 1991;1:69-99.

Goodman GS, Hirschman JE, Hepps D, Rudy L. Children's memory for stressful events. MerrillPalmer Quarterly 1991;37:109-157. 
Goodman GS, Quas JA, Batterman-Faunce JM, Riddlesberger MM, Kuhn J. Children's reactions to and memory for a stressful event: Influences of age, anatomical dolls, knowledge, and parental attachment. Applied Developmental Science 1997;1:54-75.

Goodman GS, Taub EP, Jones DP, England P, Port LK, Rudy L, Prado L. Testifying in criminal court: Emotional effects on child sexual assault victims. Monographs of the Society for Research in Child Development 1992;57(5) Serial No. 229.

Gordon BN, Baker-Ward L, Ornstein PA. Children's testimony: A review of research on memory for past experiences. Clinical Child \& Family Psychology Review 2001;4:157-181. [PubMed: 11771794]

Howe ML. Misleading children's story recall: Forgetting and reminiscence of the facts. Developmental Psychology 1991;27:746-762.

Howe ML, Courage ML, Bryant-Brown L. Reinstating preschoolers' memories. Developmental Psychology 1993;29:854-869.

Jones DP, Krugman RD. Can a three-year-old child bear witness to her sexual assault and attempted murder? Child Abuse \& Neglect 1986;10:253-258. [PubMed: 3708427]

Koenig MA, Harris PL. Preschoolers mistrust and ignore inaccurate speakers. Child Development 2005;76:1261-1277. [PubMed: 16274439]

LaRooy DL, Pipe M, Murray JE. Reminiscence and hypermnesia in children's eyewitness memory. Journal of Experimental Child Psychology 2005;90:235-254. [PubMed: 15707861]

Leichtman MD, Ceci SJ. The effects of stereotypes and suggestions on preschoolers' reports. Developmental Psychology 1995;31:568-578.

Lindsay DS, Johnson MK, Kwon P. Developmental changes in memory source monitoring. Journal of Experimental Child Psychology 1991;52:297-318. [PubMed: 1770330]

Loftus EF. The malleability of human memory. American Scientist 1979;67:312-320. [PubMed: 475150]

Malloy LC, Lyon TD, Quas JA. Filial dependency and recantation of child sexual abuse allegations. Journal of the American Academy of Child \& Adolescent Psychiatry 2007;46:162-170. [PubMed: 17242619]

Melnyk L, Bruck M. Timing moderates the effects of repeated suggestive interviewing on children's eyewitness memory. Applied Cognitive Psychology 2004;18:613-631.

Ornstein PA. Children's long-term retention of salient personal experiences. Journal of Traumatic Stress 1995;8:581-605. [PubMed: 8564274]

Ornstein PA, Baker-Ward L, Gordon BN, Merritt KA. Children's memory for medical experiences: Implications for testimony. Applied Cognitive Psychology 1997;11:S87-S104.

Ornstein PA, Gordon BN, Larus DM. Children's memory for a personally experienced event: Implications for testimony. Applied Cognitive Psychology 1992;6:49-60.

Peterson C. Children's memory for medical emergencies: 2 years later. Developmental Psychology 1999;35:1493-1506. [PubMed: 10563737]

Peterson C, Moores L, White G. Recounting the same events again and again: Children's consistency across multiple interviews. Applied Cognitive Psychology 2001;15:353-371.

Peterson C, Pardy L, Tizzard-Drover T, Warren KL. When initial interviews are delayed a year: Effect on children's 2-year recall. Law and Human Behavior 2005;29:527-541. [PubMed: 16254741]

Poole, DA.; Lamb, ME. Investigative interviews of children: A guide for helping professionals. Washington, DC: American Psychological Association; 1998.

Poole DA, Lindsay DS. Interviewing preschoolers: Effects of nonsuggestive techniques, parental coaching, and leading questions on reports of nonexperienced events. Journal of Experimental Child Psychology 1995;60:129-154.

Poole DA, Lindsay DS. Children's eyewitness reports after exposure to misinformation from parents. Journal of Experimental Psychology: Applied 2001;7:27-50. [PubMed: 11577617]

Poole, DA.; Lindsay, DS. Children's suggestibility in the forensic context. In: Eisen, ML.; Quas, JA.; Goodman, GS., editors. Memory and suggestibility in the forensic interview. Mahwah, NJ: Erlbaum; 2002. p. 355-384. 
Quas JA, Goodman GS, Bidrose S, Pipe M-E, Craw S, Ablin DS. Emotion and memory: Children's long-term remembering, forgetting, and suggestibility. Journal of Experimental Child Psychology 1999;72:235-270. [PubMed: 10074380]

Quas JA, Schaaf JM. Children's memories of experienced and nonexperienced events following repeated interviews. Journal of Experimental Child Psychology 2002;83:304-338. [PubMed: 12470963]

Quas, J.; Schaaf, JM.; Alexander, KW.; Goodman, GS. Do you really remember it happening or do you only remember being asked about it happening? Children's source monitoring in forensic contexts. In: Roberts, KP.; Blades, M., editors. Children's source monitoring. Mahwah, NJ: Erlbaum; 2000. p. 197-226.

Quas JA, Thompson WC, Clarke-Stewart A. Do jurors "know" what isn't so about child witnesses? Law and Human Behavior 2005;29:425-456. [PubMed: 16133948]

Reyna VF, Brainerd CJ. Fuzzy-trace theory: Some foundational issues. Learning and Individual Differences 1995;7:145-162.

Roberts KP. Children's ability to distinguish between memories from multiple sources: Implications for the quality and accuracy of eyewitness statements. Developmental Review 2002;22:403-435.

Roberts, KP.; Blades, M., editors. Children's source monitoring. Mahwah, NJ: Erlbaum; 2000.

Schneider, W. Memory development in childhood. In: Goswami, U., editor. Blackwell handbook of childhood cognitive development. Malden, MA: Blackwell; 2002. p. 236-256.

Scullin MH, Ceci SJ. A suggestibility scale for children. Personality and Individual Differences 2001;30:843-856.

Siegal M, Waters LJ, Dinwiddy LD. Misleading children: Causal attributions for inconsistency under repeated questioning. Journal of Experimental Child Psychology 1988;45:438-456.

Sternberg KJ, Lamb ME, Orbach Y, Esplin P. Use of a structured investigative protocol enhances young children's responses to free-recall prompts in the course of forensic interviews. Journal of Applied Psychology 2001;86:997-1005. [PubMed: 11596815]

Thompson WC, Clarke-Stewart KA, Lepore SJ. What did the janitor do? Suggestive interviewing and the accuracy of children's accounts. Law \& Human Behavior 1997;21:405-426.

Tobey AE, Goodman GS. Children's eyewitness memory: Effects of participation and forensic context. Child Abuse \& Neglect 1992;16:779-796. [PubMed: 1486508]

Welch-Ross MK. Interviewer knowledge and preschoolers' reasoning about knowledge states moderate suggestibility. Cognitive Development 1999;14:423-442.

\section{Appendix}

\section{Final Interview Questions}

\section{Free-Recall Prompts}

1. I need to you to tell me what happened when you played in this room.

2. I wasn't there in that room with you, so I need you to tell me everything you can remember about what happened.

3. Can you remember anything else about what happened in the playroom? Tell me anything else.

\section{Direct Questions}

Encouragement \#1; "I have some more questions about what happened when you played in this room [interviewer pointed to photograph of room]. Maybe these questions will help you remember more about what happened when you played." For children in the biased interviewer condition, the statement, "with my friend Todd [Chris]" was added to the end of the second sentence while the interviewer pointed to the confederate's photograph. 
1. Look at the picture of this man [interviewer pointed to confederate's photograph]. Did you play with this man in that room? ${ }^{\mathrm{a}}$

2. Did something bad happen with this man? ${ }^{\mathrm{a}}$

3. What bad things happened?

4. How many times did you play in this room? ${ }^{b}$

5. Did you color a picture by yourself? ${ }^{b}$

6. Did the man do something yucky when you were in this room?

7. Were there stickers in this room?

8. Did the man grab stickers off of the cabinet? ${ }^{\mathrm{a}}$

9. Were you playing all by yourself in this room? ${ }^{b}$

Encouragement \#2: "You are doing a great job. See, we are almost finished with the questions. I just have a few more about the time you came here and played in this room." For children in the biased interviewer condition, the statement "with my friend Todd [Chris]" was added to the end of the second sentence while the interviewer pointed to the photograph of the confederate.

10 That man wore a magic cape, didn't he? ${ }^{\mathrm{a}}$

11 Who was in this room with you when you played in there? ${ }^{b}$

12 Why did the man get in trouble? ${ }^{a}$

13 Did this man give you a kiss in that room? ${ }^{a}$

14 Did the man touch you anywhere when you were in there?

15 There weren't any mirrors or windows in this room, were there?

16 16. Where did the man touch you? ${ }^{\mathrm{a}}$

${ }^{a}$ False detail-specific and misleading questions about the man that were combined to create the false detail direct question proportion scores.

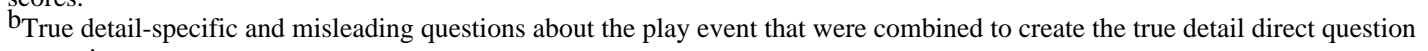
proportion scores.

${ }^{\mathrm{c}}$ This question was not included in the true or false detail proportion computations because it was misleading but did not concern the man's activities. Two other direct questions were asked but were not included in the proportion scores: "What games did you play in this room?" and "What did you do with the puppets?" 


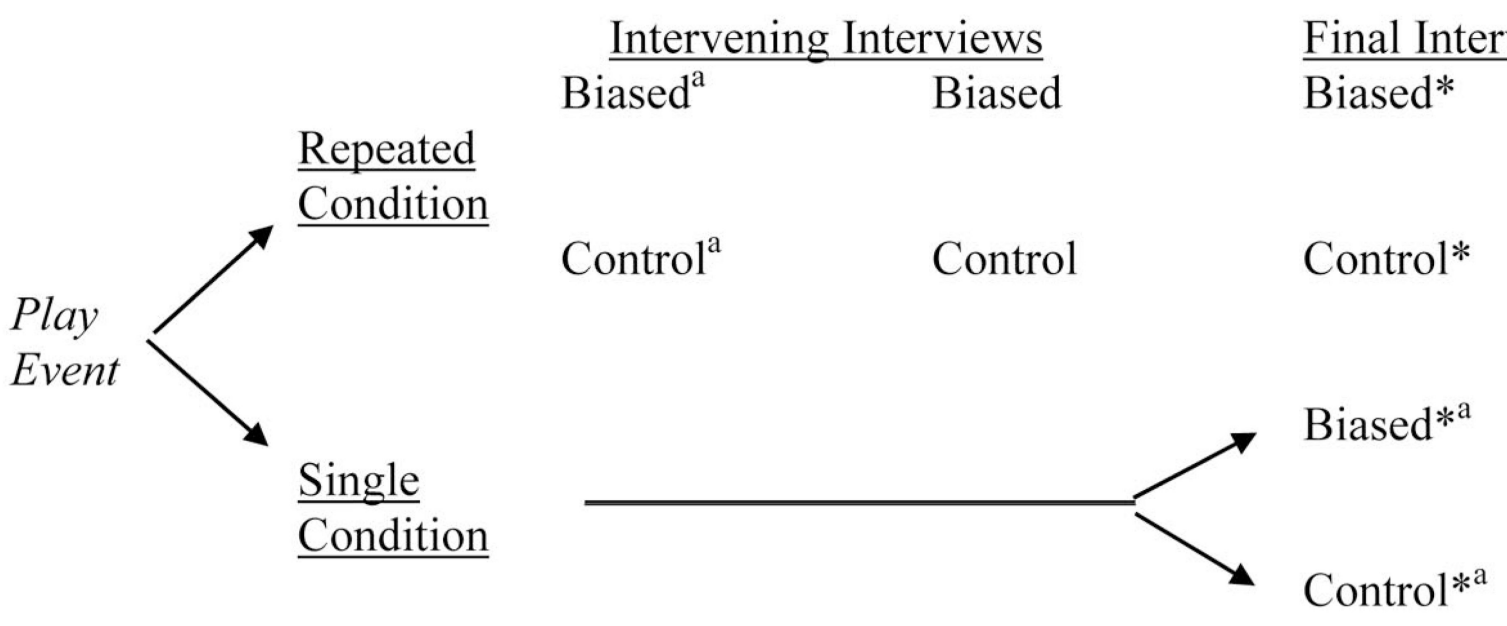

Figure 1.

A flow chart of study design. All children experienced the same initial play event, which involved playing alone. Children were exposed to either one interview following a 3-week delay or three interviews each separated by 1 week. Interviews were conducted by either a biased interviewer who implied children played with a man or by a control interviewer. The asterisks denote the experimental groups compared in the main 2 (age: 3-vs. 5-year-olds) $\times$ 2 (interview repetition: single vs. repeated) $\times 2$ (interviewer bias: biased vs. control) analyses. The superscripts denote the experimental groups compared in the subsequent 2 (age) $\times 2$ (interviewer bias) $\times 2$ (delay: short vs. long) analyses. 


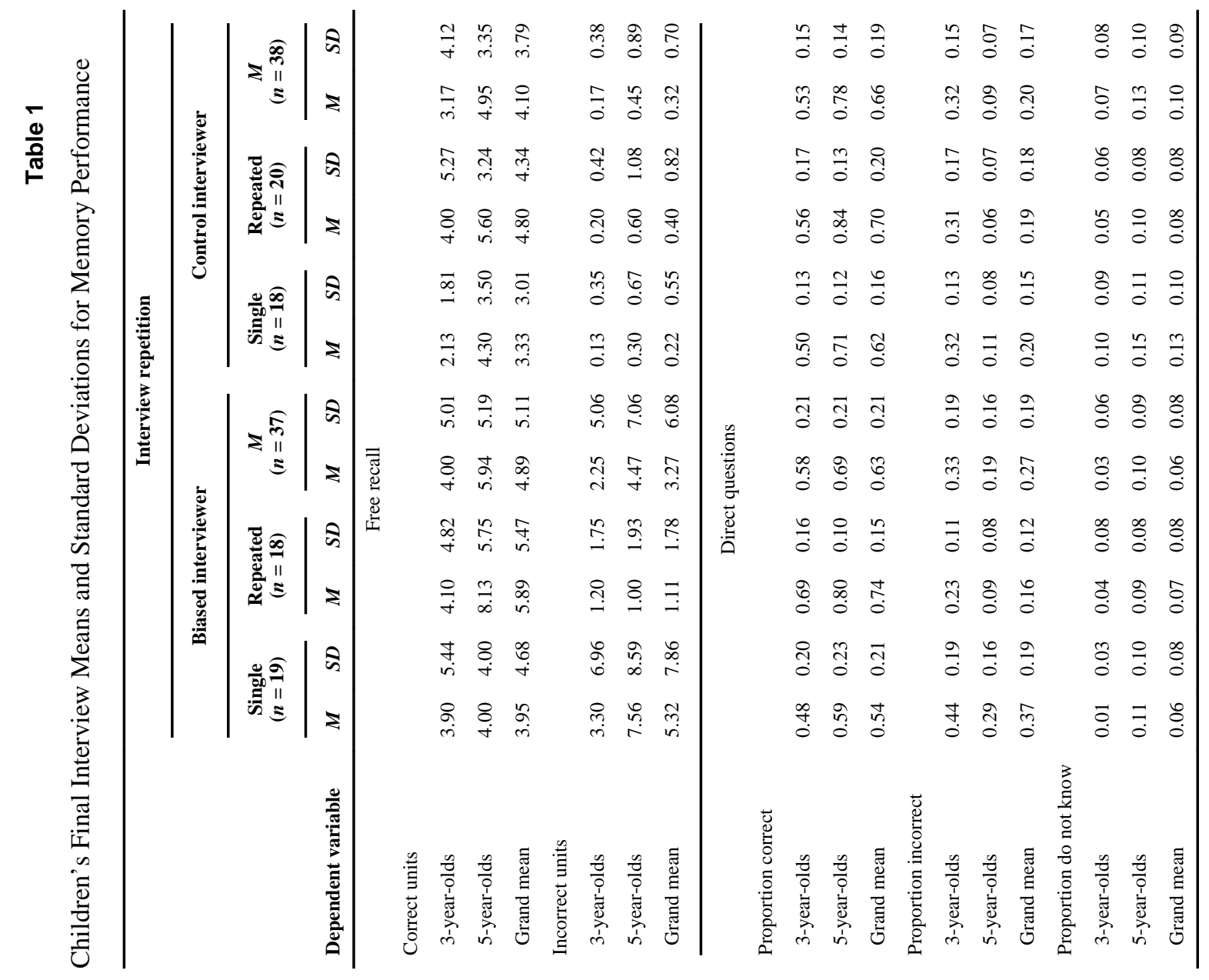




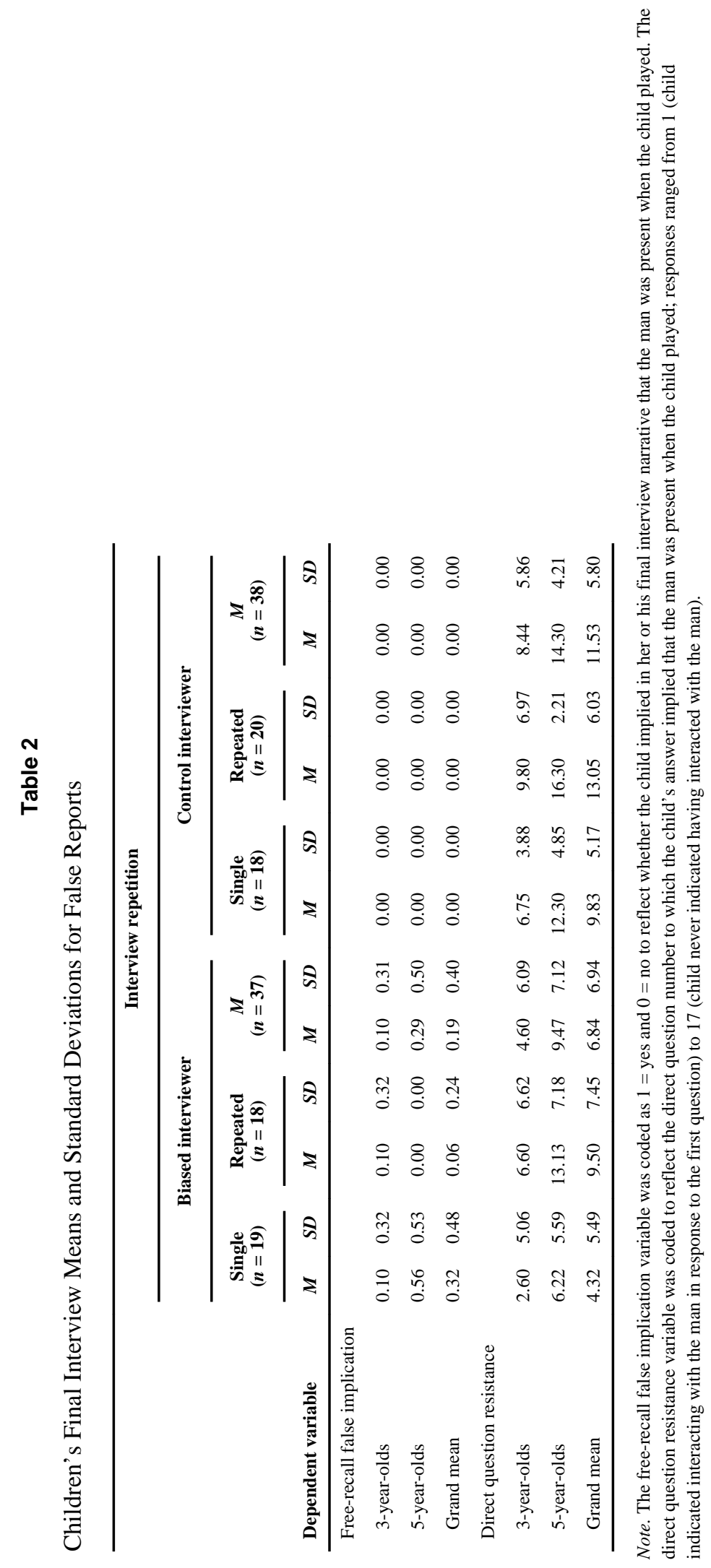


